\title{
Formation of Free Fatty Acid and Ceramide During Brain Handling: Lability of Sphingomyelin
}

\author{
Gayatri D. Deshmukh and Norman S. Radin \\ Mental Health Research Institute and Department of Biological Chemistry, The University of Michigan, \\ Ann Arbor, Michigan, U.S.A.
}

\begin{abstract}
Intact brain and brain homogenates readily form free fatty acids and ceramides, even in the cold during subcellular isolation procedures. The fatty acid formation is slightly stimulated by chelators and might be due to phospholipid hydrolysis by lysosomal phospholipases. The ceramide formation is accompanied by loss of sphingomyelin and is apparently due to the action of neutral, metal ion-activated sphingomyelinase. The latter reaction is inhibited by EDTA whereas both degradative
\end{abstract}

processes are inhibited by mercuriphenylsulfonate, the thiol-reacting inhibitor. Cerebroside does not seem to be a source of accumulated ceramide. Key Words: Sphingomyelinase-_Galactocerebrosidase-Ceramide formation-Free fatty acid formation. Deshmukh G. D. and Radin N. S. Formation of free fatty acid and ceramide during brain handling: Lability of sphingomyelin. $J$. Neurochem. 44, 1152-1155 (1985).
Free fatty acids appear rapidly in brain during anoxia and seizures and after death (Lunt and Rowe, 1968; Bazan, 1970; Cenedella et al., 1975; Rodriquez de Turco et al., 1983), apparently due primarily to the action of phospholipases on phospholipids. Their appearance may be ascribed to the hydrolytic segment of the normal process of turnover, which becomes visible when the synthetic segment stops, but there is also the possibility that hydrolases become activated during these "stresses." In preliminary studies of ceramide (Cer) concentration in brain (Selvam and Radin, 1981), we noticed that this lipid also increases after death. Two hypotheses presented themselves: (1) the Cer and free fatty acid (FFA) concentrations may increase during other brain handling procedures of interest to biochemists, and (2) the Cer is derived from one or more of the major sphingolipids. Measurements and tests established that both lipids do indeed accumulate during mild, typical manipulations of brain tissue and that much of the Cer is derived from the breakdown of sphingomyelins (Sph) by neutral sphingomyelinase. Because Cer and FFA are lipid precursors and because of the strong effects of FFA on many enzymes, neu- rochemists carrying out subcellular fractionations and incubations are advised to keep these factors in mind.

\section{MATERIALS AND METHODS}

Young rats and mice of various ages were used; these were Hsd:Sprague-Dawley (SD)BR rats, ICR mice, and CD-1 mice (Harlan Sprague-Dawley, Indianapolis and Charles River Breeding Labs). They were maintained on Lab Chow for a few days prior to use in a room with a 1:1 light-dark cycle. Where tests with whole brains were run, the animals were divided into subgroups of five in such a way as to produce groups with very similar average body weights and weight distributions ("stratified samples"). The brains were removed within 30-40 s after decapitation and stored at $37^{\circ} \mathrm{C}$ or dropped into pentane surrounded by dry ice. The five brains in each group were pooled for analysis. Each zero time or treatment group consisted of two five-animal subgroups.

Lipids were extracted with hexane-2-propanol, $3: 2$, using $24 \mathrm{ml}$ for each gram of brain and, where buffer was present, with $33 \mathrm{ml}$ for each milliliter of water (Radin, 1981). An aliquot of each extract was analyzed for FFA, Cer, and Sph content by a combination of partitioning, TLC, charring, and densitometry by scintillationquenching (Radin et al., 1982). Each aliquot was deter-
Received May 3, 1984: accepted October 1, 1984

Address correspondence and reprint requests to Dr. Norman Radin, Neuroscience Lab. Bldg., 1103 E. Huron, Ann Arbor, MI 48109, U.S.A.
Abbreviations used: FFA, Free fatty acids; Cer, Ceramides; Sph, Sphingomyelins. 
mined by evaluating two spots and comparing them with standards.

Incubations were carried out in $50 \mathrm{mM}$ Tris- $\mathrm{Cl}^{-}, \mathrm{pH}$ 7.4 (measured at room temperature).

\section{RESULTS}

In one test, intact rat brains were left for $30 \mathrm{~min}$ in moist Petri dishes at $37^{\circ} \mathrm{C}$. The FFA concentration rose $485 \%$ but the Cer level rose only $16 \%$ (Table 1). In another test, increases of $10-31 \%$ were observed in Cer.

Brains from other rats in the same set of animals were stored at $-70^{\circ} \mathrm{C} 1 \mathrm{day}$, then homogenized in four volumes of $0.32 \mathrm{M}$ sucrose prepared in Tris buffer. The homogenate from group 3 was stored in ice for $90 \mathrm{~min}$, centrifuged for $30 \mathrm{~min}$ at $178,000 \times$ $g$, and the resultant pellet transferred with $3 \mathrm{ml}$ of Tris to a glass vessel, in which it was lyophilized overnight. The dry membranes were analyzed for lipids after rehydration with $0.8 \mathrm{ml}$ water $/ \mathrm{g}$ original brain weight. Group 4 was treated similarly but with an incubation for $60 \mathrm{~min}$ at $37^{\circ} \mathrm{C}$ instead of the initial 90 -min storage in ice. The 90-min storage in ice was intended to simulate a series of ultracentrifugation fractionation procedures. Simple storage of the homogenates, even at $0^{\circ} \mathrm{C}$, produced large increases in FFA and Cer (Table 1). The homogenate incubated at the higher temperature, which simulates an enzymatic incubation followed by a subcellular fractionation to localize the products, yielded an even larger increase in both lipids.

In a shorter treatment, in which the lyophilization step was omitted, the pellet obtained by centrifugation in the cold for $30 \mathrm{~min}$ at $178,000 \times g$ was found to contain $83 \%$ more FFA and $34 \%$ more Cer.

A similar experiment was done with a rat brain, but with fewer manipulations. Here, the quickly frozen brain was stored less than a day in dry ice, homogenized in five volumes of buffer, and dispensed in $1.25-\mathrm{ml}$ portions into test tubes. One pair of tubes was promptly extracted with solvent, while another pair of tubes was incubated at $37^{\circ} \mathrm{C}$ for 60 min, then extracted. A third pair was incubated similarly but in the presence of $0.6 \mu \mathrm{mol}$ each of palmitic and oleic acids. The fatty acids, which biock

TABLE 1. Accumulation of FFA and Cer in rat brain

\begin{tabular}{lcc}
\hline \multicolumn{1}{c}{ Treatment } & $\begin{array}{c}\text { FFA } \\
\text { (ng/mg brain) }\end{array}$ & $\begin{array}{c}\text { Cer } \\
\text { (ng/mg brain) }\end{array}$ \\
\hline $\begin{array}{l}\text { Zero-time control } \\
\text { Intact brain, } 30 \text { min at } 37^{\circ} \mathrm{C}\end{array}$ & $661 \pm 20$ & $171 \pm 9$ \\
$\begin{array}{l}\text { Homogenate, left at } 0^{\circ} \text {, then } \\
\text { centrifuged (pellet only) }\end{array}$ & $533 \pm 41$ & $640 \pm 23$ \\
$\begin{array}{c}\text { Homogenate, left at } 37^{\circ} \mathrm{C} \text {, then } \\
\text { centrifuged (pellet only) }\end{array}$ & $883 \pm 47$ & $856 \pm 17$ \\
\hline
\end{tabular}

The data and standard deviations are derived from 10 brains, from two pools of five each, with each pool extract analyzed in duplicate. lysosomal ceramidase (Gatt, 1966), were added in an attempt to prevent loss of Cer during the incubation. Comparison with the zero-time controls (Table 2) showed that the 60 -min incubation produced a $525 \%$ rise in FFA and a $252 \%$ rise in Cer. The inclusion of exogenous FFA did not exert a distinct effect on Cer accumulation.

To test the possibility that galactosyl Cer, the predominant brain sphingolipid, is the primary source of the observed Cer accumulations, we included galactonolactone in some incubations. This lactone inhibits cerebroside galactosidase (Arora et al., 1973). The lactone $(17 \mathrm{mM})$ and brain homogenate from 30-day mice were incubated as described in Table 2. The nonincubated control contained 374 and $151 \mathrm{ng} / \mathrm{mg}$ of FFA and Cer, respectively. After $60 \mathrm{~min}$ at $37^{\circ} \mathrm{C}$, the homogenate showed increases in the two lipids of $418 \%$ and $555 \%$. The samples containing the lactone showed similar increases, $483 \%$ and $539 \%$. This appears to rule out cerebroside as a significant source of Cer under these conditions. Also making it improbable was the failure in all incubations to find $\mathrm{Cer}$ containing hydroxy fatty acids.

The second largest potential source of Cer is Sph, which is subject to hydrolysis by a lysosomal, acid sphingomyelinase (Yamanaka et al., 1981), and by a neutral, $\mathrm{Mg}^{2+}$-dependent hydrolase (Rao and Spence, 1976; Gatt, 1982). The increase in Cer observed in the above experiment $(839 \mathrm{ng} / \mathrm{mg})$, if derived from a molar equivalent of $\mathrm{Sph}$, would decrease the tissue level of Sph by roughly 1,040 ng/ $\mathrm{mg}$. Analysis of the lipid extracts showed that the Sph content of the unincubated homogenate was $1,700 \mathrm{ng} / \mathrm{mg}$ and that of the incubated sample was $620 \mathrm{ng} / \mathrm{mg}$. This decrease of $1,080 \mathrm{ng} / \mathrm{mg}$ corresponds strikingly well to the amount of Cer formed during the incubation.

A second experiment was run with 66-day-old ICR mice at a brain concentration of $167 \mathrm{mg} / \mathrm{ml}$, under the usual incubation conditions. The unincubated homogenate was found to contain $108 \mathrm{ng} /$ $\mathrm{mg}$ of Cer and $1,710 \mathrm{ng} / \mathrm{mg}$ of Sph. After $60 \mathrm{~min}$ of incubation, the samples contained $447 \mathrm{ng} / \mathrm{mg}$ of $\mathrm{Cer}$ and $1,400 \mathrm{ng} / \mathrm{mg}$ of Sph. Here the changes $(+339$ and $-310 \mathrm{ng} / \mathrm{mg}$, respectively) were smaller but

TABLE 2. Formation of FFA and Cer in rat brain homogenate incubated at $37^{\circ} \mathrm{C}$ at $\mathrm{pH} 7.4$

\begin{tabular}{lcc}
\multicolumn{1}{c}{ Treatment } & $\begin{array}{c}\mathrm{FFA}^{a} \\
\text { (ng/mg brain) }\end{array}$ & $\begin{array}{c}\mathrm{Cer}^{u 4} \\
\text { (ng/mg brain) }\end{array}$ \\
\hline $\begin{array}{lcc}\text { Zero-time control } \\
\text { Incubated 60 min }\end{array}$ & 232,231 & 178,177 \\
$\begin{array}{l}\text { Incubated with FFA }(0.6 \mu \mathrm{mol} \\
\text { each of oleic and palmitic) }\end{array}$ & $1,420,1,470$ & 629,623 \\
\hline
\end{tabular}

${ }^{a}$ Values shown are averages of duplicate analyses from two incubations. 
they were again in approximate agreement with the idea that $\mathrm{Sph}$ is the primary source of Cer. With brain incubated in the presence of $5 \mathrm{~m} M$ EDTA, the Cer increase was much smaller (only $61 \mathrm{ng} / \mathrm{mg}$ ) and the loss of Sph was also smaller $(230 \mathrm{ng} / \mathrm{mg})$. The effect of EDTA on Cer accumulation supports the conclusion that the $\mathrm{Mg}^{2+}$-dependent sphingomyelinase is the major source of Cer. In this experiment, the formation of FFA (which increased 418\%) was not inhibited by EDTA. In fact, the increase with EDTA present $(493 \%)$ was larger.

A further examination was carried out with a thiol-binding mercurial and a more selective chelator, ethylene glycol-bis( $\beta$-aminoethyl ether)$N, N, N^{\prime}, N$ 'tetraacetic acid ("EGTA"), which binds $\mathrm{Mg}^{2+}$ relatively poorly in comparison to $\mathrm{Ca}^{2+}$ and does not inhibit the neutral sphingomyelinase. Here, using brains from 86-day ICR mice, the changes were smaller than before but the results were similar (Table 3 ). EDTA again greatly reduced the formation of Cer and disappearance of Sph (and again stimulated the appearance of FFA), whereas EGTA produced only small effects. A similar difference in the effects of these chelators was reported for the divalent metal cation-activated sphingomyelinase of human brain (Rao and Spence, 1976).

p-Chloromercuriphenylsulfonate, $1 \mathrm{~m} M$, lowered the formation of both Cer and FFA and decreased the loss of Sph. The effects on Cer and Sph are in agreement with the observation (Rao and Spence, 1976) that thiol binders greatly inhibit neutral sphingomyelinase.

\section{DISCUSSION}

The primary significance of our findings is that large changes can take place in brain tissue during handling procedures that are commonly thought to have little effect on the chemical composition of brain membranes. Storage in the cold, subcellular fractionation, and incubations at $37^{\circ} \mathrm{C}$ produced distinct changes in the tissue levels of FFA, Cer, and Sph. Lunt and Rowe (1968) and Pediconi et al. (1981) have already pointed out some of these effects with respect to FFA. Many reports in the lit-

TABLE 3. Effects of chelators and thiol binder on brain lipids

\begin{tabular}{lccc}
\hline \multicolumn{1}{c}{ Treatment } & FFA & Cer & Sph \\
\hline Zero-time control & $188 \pm 21$ & $125 \pm 7$ & $1,750 \pm 80$ \\
Incubated $60 \mathrm{~min}$ at $37^{\circ} \mathrm{C}$ & $814 \pm 60$ & $395 \pm 14$ & $1,430 \pm 50$ \\
Incubated with $5 \mathrm{~m} M$ EDTA & $867 \pm 31$ & $156 \pm 7$ & $1,680 \pm 90$ \\
$\begin{array}{l}\text { Incubated with } 5 \mathrm{~m} M \text { EGTA } \\
\text { Incubated with } 1 \mathrm{mM}\end{array}$ & $859 \pm 17$ & $343 \pm 15$ & $1.500 \pm 50$ \\
$\quad$ mercurial &
\end{tabular}

Mouse brains from 86-day-old animals were pooled and incubated after homogenization at $167 \mathrm{mg} / \mathrm{ml}$. Data show averages of four measurements $\pm \mathrm{SD}$

"p-Chloromercuriphenyl sulfonate. erature have shown that FFA stimulate or inhibit enzymes and form complexes with proteins. The changes in Cer and Sph levels may be of importance to workers assaying sphingolipid enzymes, particularly in the presence of EDTA or divalent metal cations. Experiments involving the binding of serum lipoproteins by cells may be dependent on Sph levels in the cells (Gatt and Bierman, 1980). Acetylcholinesterase, which binds Sph (Watkins et al., 1977), may be similarly sensitive.

The changes we observed must have produced changes in membrane fluidity, a factor commonly believed to affect membrane enzymes and permeability.

Our study used only a few illustrative conditions of handling and the choice of buffer $\mathrm{pH}$ and type, species of animal, organ, and animal age may be important.

The inclusion of EDTA in homogenized tissue is often found to be beneficial, and it may be that its effect on Sph breakdown is important in some of these cases.

Incubation of intact brain (Table 1) did not produce a large rise in Cer. Perhaps the Sph in intact plasma membranes is physically not close to neutral sphingomyelinase, but the two substances make sufficient contact for catalysis to occur during the handling of homogenates. Such a membrane $/ \mathrm{mem}$ brane phenomenon was observed in chicken erythrocytes, in which $\mathrm{Sph}$ is relatively stable until the cells are hemolyzed (Record et al., 1980). Actual transmembrane hydrolysis was demonstrated.

It is possible that some of the Cer formed during our experiments was converted to FFA and sphingosine by the neutral ceramidase (Sugita et al., 1975). This reaction could explain some of the discrepancies noted between the amounts of Cer formed and the amounts of Sph destroyed.

The failure of EDTA and EGTA to block FFA formation is intriguing, in view of the known dependence of most phospholipases on divalent metal cations. There are lysosomal phospholipases that do not require $\mathrm{Ca}^{2+}$ and that are unaffected by EDTA. However, they are said to be stimulated by $\mathrm{Hg}^{2+}$ (Hostetler et al., 1982), and thus, on the basis of our experiment with the mercurial inhibitor, may not be the catalytic agent producing FFA. Arachidonic acid was found to be released during the incubation of brain synaptosomes at $\mathrm{pH} 7.4$ and the inclusion of $1 \mathrm{~m} M$ EDTA had little effect here too (Majewska et al., 1981).

We did not use liquid nitrogen cooling after decapitation, prior to removal of the brain. It was felt that the essence of the findings was unaffected by the higher zero time values we obtained for the FFA.

Acknowledgments: This work was supported by USPHS grant NS-03192. We are indebted to Inez Mason for vital laboratory support. 


\section{REFERENCES}

Arora R. C., Lin Y.-N., and Radin N. S. (1973) The inhibitorsensitive sites of galactosyl ceramide galactosidase. Arch. Biochem. Biophys. 156, 77-83.

Bazan N. G. (1970) Effects of ischemia and electroconvulsive shock on free fatty acid pool in the brain. Biochim. Biophys. Acta 218, 1-10.

Cenedella R. J., Galli C., and Paoletti R. (1975) Brain free fatty acid levels in rats sacrificed by decapitation versus focused microwave irradiation. Lipids 10, 290-293.

Gat1 S. (1966) Enzymatic hydrolysis of sphingolipids. Hydrolysis and synthesis of ceramides by an enzyme from rat brain. $J$. Biol. Chem. 241, 3724-3730.

Gatt S. (1982) Studies on sphingomyelinase, in Phospholipids in the Nervous System, Vol. I: Metabolism (Horrocks L. A., Ansell G. B., and Porcellati G., eds), pp. 181-197. Raven Press, New York.

Gatt S. and Bierman E. L. (1980) Sphingomyelin suppresses the binding and utilization of low density lipoproteins by skin fibroblasts. J. Biol. Chem. 255, 3371-3376.

Hostetler K. Y., Yazaki P. J., and van den Bosch H. (1982) Purification of lysosomal phospholipase A. Evidence for multiple isoenzymes in rat liver. J. Biol. Chem. 257, 1336713373.

Lunt G. G. and Rowe C. E. (1968) The production of unesterified fatty acid in brain. Biochim. Biophys. Acta 152, 681693.

Majewska M. D., Manning R., and Sun, G. Y. (1981) Effects of postdecapitative ischemia on arachidonate release from brain synaptosomes. Neurochem. Res. 6, 567-576.

Pediconi M. F., Rodriguez de Turco E. B., and Bazan N. G. (1981) Metabolism of arachidonic acid in the neural tissue, in New Trends in Nutrition, Lipid Research, and Cardio- vascular Diseases (Bazan N. G., Paoletti R., and lacono J. M., eds), pp. 17-23. Alan R. Liss, New York.

Radin N. S. (1981) Extraction of tissue lipids with a solvent of low toxicity. Methods Enzymol. 72, 5-7.

Radin N. S., Deshmukh G. D., Selvam R., and Hospattankar A. V. (1982) Determination of glucocerebroside, sphingomyelin, free fatty acid and total lipid by thin-layer chromatography and charring-scintillation quenching. Biochim. Biophys. Acta 713, 474-478.

Rao B. G. and Spence M. W. (1976) Sphingomyelinase activity at $\mathrm{pH} 7.4$ in human brain and a comparison to activity at pH 5.0 J. Lipid Res. 17, 506-515.

Record M., Loyter A., and Gatt S. (1980) Utilization of membranous lipid substrates by membranous enzymes. Biochem. J. 187, 115-121.

Rodriguez de Turco E. B., Morelli de Liberti S., and Bazan N. G. (1983) Stimulation of free fatty acid and diacylglycerol accumulation in cerebrum and cerebellum during bicuculline-induced status epilepticus. Effect of pretreatment with $\alpha$-methyl-p-tyrosine and $p$-chlorophenylalanine. $J$. Neurochem. 40, 252-259.

Selvam R. and Radin N. S. (1981) Quantitation of lipids by charring on thin-layer plates and scintillation quenching: application to ceramide determination. Anal. Biochem. 112,338345.

Sugita M., Williams M., Dulaney J. T., and Moser H. W. (1975) Ceramidase and ceramide synthesis in human kidney and cerebellum. Description of a new alkaline ceramidase. Biochim. Biophys. Acta 398, 125-131.

Watkins M. S., Hitt A. S., and Bulger J. E. (1977) The binding of $18 \mathrm{~S}$ acetylcholinesterase to sphingomyelin and the role of the collagen-like tail. Biochem. Biophys. Res. Commun. $79,640-647$.

Yamanaka T., Manada E., and Suzuki, K. (1981) Acid sphingomyelinase of human brain. J. Biol. Chem. 256, 38843889 . 